\title{
3D LOCAL SCALE SOLAR RADIATION MODEL BASED ON URBAN LIDAR DATA
}

\author{
P. Redweik ${ }^{\mathrm{ab} *}$, C. Catita ${ }^{\mathrm{ac}}$, M.C. Brito ${ }^{\text {ad }}$ \\ a Faculdade de Ciências Universidade de Lisboa, Dept.Engenharia Geográfica, Geofísica e Energia \\ b Centro de Geologia da Universidade de Lisboa \\ c LATTEX/Instituto Geofísico D.Luís, \\ d Instituto Geofísico D. Luís, \\ Campo Grande, \\ 1749-016 Lisboa, Portugal \\ (pmredweik,ccatita,mcbrito@fc.ul.pt)
}

KEY WORDS: Solar Radiation, Urban, Modelling, LIDAR, GIS

\begin{abstract}
The aim of the present study is to obtain the direct, diffuse and reflected solar energy that reaches a generic point of an urban landscape regardless of its location on a roof, on the ground or on a façade. The vertical façades embody a discontinuity in a digital elevation surface function and most models fail in the determination of solar radiation for points on façades. The presented algorithm solves the problem in an integrated way: starting with a georreferenced LIDAR data cloud covering a $400 \times 400 \mathrm{~m}^{2}$ urban area resampled in a $1 \mathrm{~m} \times 1 \mathrm{~m}$ mesh, applies a new shadow algorithm over roofs, terrain and façades for each time frame, applies the Kumar solar radiation model for the calculation of direct, diffuse and reflected irradiation for each $1 \mathrm{x} 1 \mathrm{~m}$ raster cell on non vertical surfaces of roof and terrain, and calculates total and mean irradiation of each 1 meter wide column of vertical façade based on the illuminated area at each time frame. The results for each time frame are integrated for the wished time period from one hour to one year, being the time steps also selectable, allowing several kinds of solar radiation and shadowing studies. GIS were used to evaluate monthly averages of solar radiation for a particular location as well as to map the photovoltaic potential of the building façades and their roofs according to determined classes of potential.
\end{abstract}

\section{INTRODUCTION}

Solar radiation models intend to estimate how much sun irradiation reaches a spot on the earth surface either in a direct or in an indirect way (diffuse and reflected irradiation). They are very useful tools in several fields of global, regional and local scale. Local scale models are used for instance in the planning of the location of photovoltaic installations, in urban planning where renewable energy sources are a priority and in determining potential energy efficiency in buildings.

The amount of sun energy striking a spot over a time period varies according to global, local, temporal, spatial and meteorological factors. An ideal solar radiation model has to take all these factors in account. Several solar radiation models have been implemented in proprietary as well as in open source software. Well known examples are the ArcGis Solar Analyst (Fu \& Rich, 1999) and the GRASS r.sun (Hofierka \& Súri, 2002). These models can work on a raster based geographic information layer, allowing to consider in the radiation model spatial changing attributes, such as slope, aspect and latitude over large regions.

A relevant issue in the calculation of solar irradiation over a period is the shadow. This is a time varying attribute of a spot on the earth surface. If a spot is in shadow or not depends not only from its constant XYZ location but also from the configuration of the neighboring objects, from its latitude, the time of the day and day of the year. All these factors determine the instantaneous direction of the sun rays and if they hit the spot at a precise moment.

When it comes to local scale, especially in urban areas where the mentioned studies are more often requested, only a 3D-model of the reality, containing buildings in all their geometric complexity, trees and other obstacles to the propagation of sun light, can deliver detailed object information for an accurate modeling. 3D-city models that associate geometry with semantic are valuable tools for this objective. Nevertheless, they are rather expensive to produce from the start for large areas, and once built, they are not so easy to integrate in calculations as raster data do, since their underlying reality description is still less compatible with attributes changing simultaneously in height and in time like shadow and sun radiation do. On the other hand, they are very advantageous when it comes to visualise results. LiDAR data has the advantage of being available for many urban areas, with sufficient quality and density, and contain the relevant object information for a local scale solar radiation model (terrain, buildings and trees).

The aim of the present study is to obtain the direct, diffuse and reflected solar energy that reaches a generic point of an urban landscape, regardless of its location on a roof, on the ground or on a vertical façade. The results are presented on maps and in perspective representations for the evaluation of the façades solar energy potential.

Since the study of the photovoltaic potential on façades becomes only relevant for buildings having large façades, the area chosen for testing the algorithm includes mainly three or more stored buildings, corresponding to part of the Campus of the University of Lisbon.

\section{METHODOLOGY}

\subsection{Test data sets}

In this study, two data sets were used. The first one is a synthetic 3D raster with 150 x150 cells containing two houses with vertical façades (figure 1). One of the houses has a flat and a 30 degrees inclined roof facing East. The single roof of the second house presents an inclination of 34 degrees facing south. This configuration was chosen in order to calibrate the applied 
radiation model since photovoltaic potential was known from global models in the area of the campus for surfaces with those characteristics (Súri et al. ,2007).

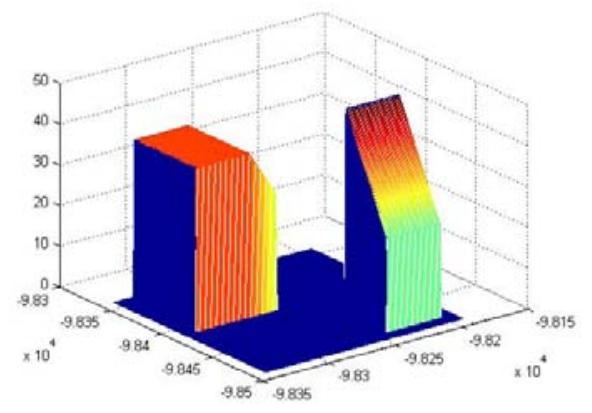

Figure 1. Synthetic data set.

The second data set was an excerpt of a 2006 LiDAR Digital Surface Model (DSM) provided by LOGICA. Elevation and intensity of the first and last pulse returns from a TopoSys II 83 $\mathrm{kHz}$ LiDAR instrument, flown on a helicopter, were recorded for each laser pulse, with an average measurement density of 20 points per $\mathrm{m}^{2}$ (fig.2). The data are resampled for a $1 \mathrm{x} 1 \mathrm{~m}^{2}$ raster and present a documented horizontal accuracy of $0.5 \mathrm{~m}$ and a vertical accuracy of $0.15 \mathrm{~m}$. It is a typical urban data set containing the buildings of the Faculty of Sciences, associated institutes, a museum and some neighbouring houses as well as part of the tree canopy of Campo Grande and the museums garden with some very high trees.

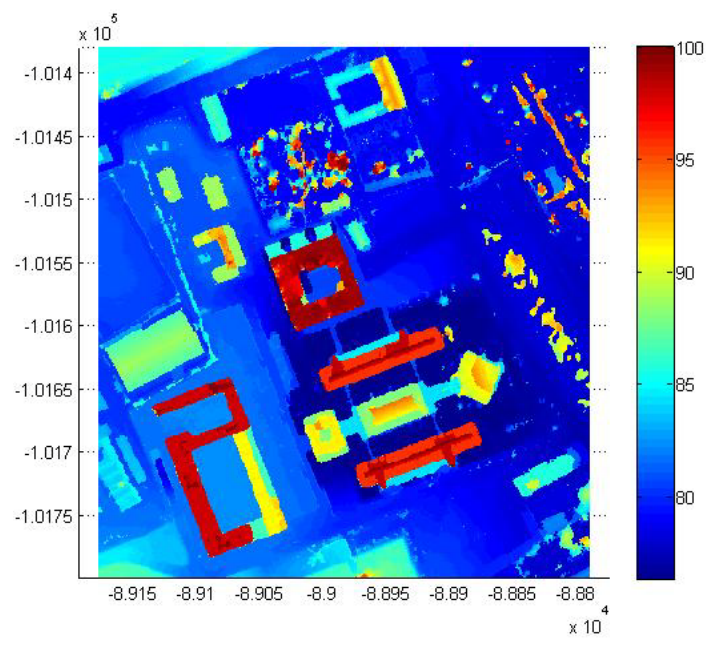

Figure 2. LiDAR data set classified according to the height [m]

\subsection{Solar radiation model}

The implemented solar radiation model follows the approach presented by Kumar in (Kumar et al., 1997). It considers the solar flux outside the atmosphere, the optical air mass, and the influence of water vapour and aerosol content of the atmosphere in the amount of solar irradiance received in a particular site. This is composed by the sum of direct, diffuse and reflected solar irradiation and concerns clear sky conditions. Starting with a solar constant value $S_{0}$ of $1367\left[\mathrm{Wm}^{-2}\right]$, corresponding to the irradiance on an area perpendicular to the sun rays outside the atmosphere at the mean Sun-Earth distance according to the World Radiation Centre, the solar irradiance throughout the year can be calculated by (1) where $\mathrm{N}$ is the number of days of the actual date since January $1^{\text {st }}$.

$$
I_{0}\left[W^{-2}\right]=S_{0}\left(1+0.0344 \cos \left(360^{\circ} . N / 365\right)\right)
$$

This irradiation is attenuated inside the atmosphere due to different factors such as absorption and scattering of the different wavelengths and atmospheric turbidity. Kumar's model uses an empirical relation between optical air mass $M$, for a sun altitude angle $\alpha$, and atmospheric transmittance for direct irradiation $\tau_{\mathrm{b}}$ expressed in equations (2), in order to calculate the shortwave solar radiation $I_{S}$ on a surface normal to the sun rays located down on Earth.

$$
\begin{aligned}
& I_{s}=I_{0} \tau_{b} \\
& \tau_{b}=0.56\left(e^{-0.65 M}+e^{-0.095 M}\right) \\
& M=\left[1229+(614 \sin \alpha)^{2}\right]^{1 / 2}-614 \sin \alpha
\end{aligned}
$$

The direct radiation striking a surface which normal makes an angle $i$ with the direction of the sun rays is $I_{p}$ according to equation (3) where $i$ depends, on one side, on the slope and aspect (azimuth) of the surface (space variables) and, on the other side, on the solar azimuth and solar altitude (time variables).

$$
I_{p}=I_{s} \cos i
$$

This parcel of the total radiation striking a particular site can be null if the spot is in shadow. On the contrary, diffuse $I_{d}$ and reflected $I_{r}$ radiation can reach a spot even if it is in shadow. These two parcels depend also on the surface slope $\beta$ and sun altitude $\alpha$ and are expressed by equations (4) where $r$ is the ground reflectance coefficient.

$$
\begin{aligned}
& I_{d}=I_{0} \tau_{d} \cos ^{2} \beta / 2 \sin \alpha \\
& I_{r}=r I_{0} \tau_{r} \sin ^{2} \beta / 2 \sin \alpha \\
& \tau_{d}=0.271-0.294 \tau_{b} \\
& \tau_{r}=0.271+0.706 \tau_{b}
\end{aligned}
$$

The formulae for sun altitude and azimuth as a function of the day of the year and the hour of the day, as well as the time for sunrise and sunset in each day were extracted from the Astronomical Almanac 2011 (Astr. Alman., 2010)

\subsection{Shadow algorithm}

At a particular time, a spot that is in the shadow doesn't receive any direct sun irradiation. Since this parcel is the most relevant for the calculation of the photovoltaic and thermal potential it is very important to consider the shadow in the model. The shadow can be seen as a time dependent binary attribute of a location (a spot is or is not in the shadow at a time). Several approaches can be adopted to calculate shadow maps of the terrain for a specified time. Most of them start with a point of interest in a 2.5D elevation model and search in the direction of the sun, along a specified radius, if there are points that can obstruct the path of sun light (Hofierka \& Súri 2002, Jochem et al. 2009). Since vertical façades embody a discontinuity in a 
2.5D digital elevation surface most models fail in the determination of solar radiation for points on façades. These are either represented with an erroneous slope or are not represented at all.

The described shadow algorithms are also not capable of calculating the shadow for points of interest that occupy the same XY, position but have a variable $Z$. An approach presented by Carneiro (2011), however, calculates shadows on façades by slicing a 3D Urban Model at several height levels (every 3 meters) and applying to each level the shadow algorithm of Ratti (2004).

The algorithm proposed in the present paper works in an integrated way requiring the same raster data set for calculating shadows on the ground, on roofs and on vertical façades (nonvertical façades are treated the same way as the ground). The raster set must contain height values of the ground and of all objects on it and must be georreferenced, for example a DSM obtained from LiDAR data.

The basic concept is that, at a particular time of the day, assuming a clear sky and a sun above the horizon, every pixel/cell of the DSM casts a shadow along a line in the opposite azimuth of the sun rays (sun azimuth $+180^{\circ}$ ). The shadow line for each pixel is considered to be a 3D straight line starting at the pixel, sharing its height and having a constant slope equals the sun altitude $\alpha$. The maximal length of the shadow line projected on the $\mathrm{XY}$ plane, $\mathrm{S}_{\max }$, is set to be the horizontal projection of the height amplitude in the actual DSM (5). That means that, at the considered time, a hypothetical vertical object as high as the maximal height difference in the DSM would cast a shadow in an horizontal plane as long as the projected maximal shadow line in the opposite direction of the sun.

$$
S_{\max }=\left(Z_{\max }-Z_{\min }\right) \cdot \cos \alpha
$$

This shadow line is interrupted whenever, along the line, a DSM cell presents a height value $\mathrm{Z}$ that is higher than the shadow line at that position. A binary shadow map with the same dimensions as the DSM is built this way for each time frame. Pixels in shadow receive the attribute 0 , illuminated pixels receive the attribute 1 .

This algorithm allows not only to detect pixels in shadow but also to extract the height of the shadow line when it reaches an obstacle, for example, a façade. For multiple shadow lines reaching the façade at the same cell (fig. 3), the greatest height is assigned to the cell position.

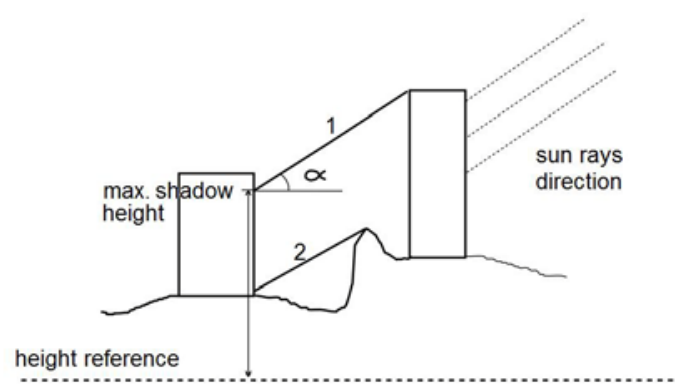

Figure 3. Assignment of shadow height to a XY façade cell: only shadow line 1 is relevant for this assignment.

A second map is built, the shadow height map, showing shadows on all non vertical surfaces just like in the first shadow map and the shadow height on all cells corresponding to vertical surfaces. These can be building façades, but also trees. Although for the objective of this model development, trees don't belong to the objects of interest, they shouldn't be filtered away from the input height data because of the shadow they cast. In this approach, trees are seen as solid shadow casting objects.

The shadow maps are used in the next steps.

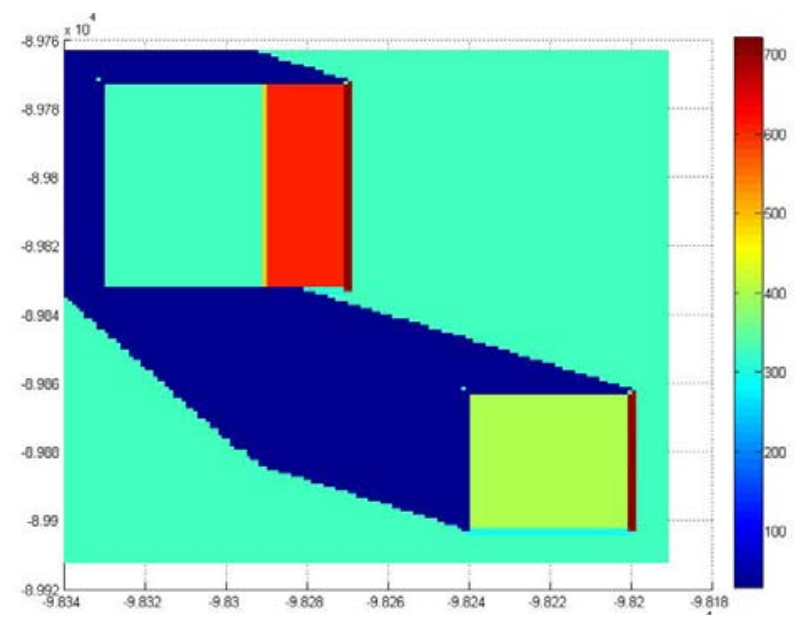

Figure 3: Direct radiation map for March, $21^{\text {st }}$ at 7 a.m. for the synthetic data set $\left[\mathrm{W} / \mathrm{m}^{2}\right]$.

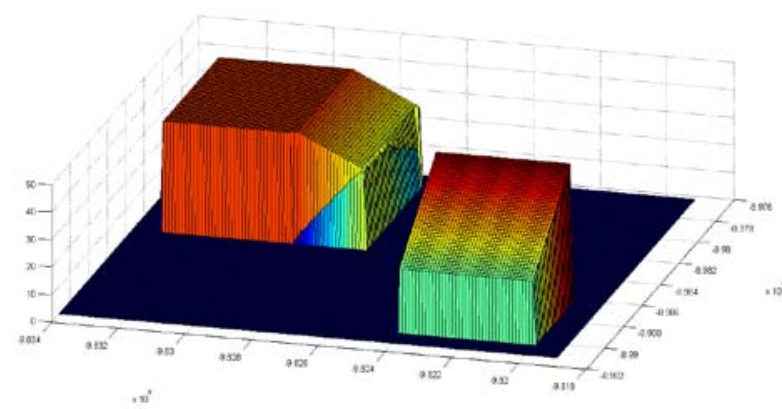

Figure 4: Shadow on the façade of the NW building casted from the SE building, coloured by height.

\subsection{Radiation at façades}

Slope and aspect are calculated for each DSM cell and stored also in separate maps. The height of the DSM cells is not relevant for the applied solar radiation calculation described in section 2.2. Taking this into account, in order to obtain the solar radiation in vertical façades, since a 2.5D DSM doesn’t contain vertical planes, every cell with an associated slope greater than $85^{\circ}$ was considered as belonging to a vertical plane and its slope value on the map was changed to $90^{\circ}$. Applying the solar radiation formulae (1) to (4) with the values of the modified slope map results in a radiation map for the whole area, where the façade cells show the sun radiation on a vertical surface with the cell size dimension, in the original position and aspect. Since aspect in each cell of the DSM is considered to be the azimuth of the steepest slope it will normally coincide in the DSM and in the actual façade.

The total radiation in a façade vertical column as wide as the cell size is calculated by multiplying the radiation of one vertical cell size obtained above by the illuminated height at the 
column XY position. The illuminated height in each façade XY position is obtained subtracting the shadow height map from the DSM.

\section{RESULTS}

The described concepts were implemented in a Matlab ${ }^{\circledR}$ routine called SOL. The Kumar solar radiation model was also implemented by Hebeler in the solarradiation Matlab function. A similar strategy was applied in the present algorithm in order to integrate the radiation calculated for a time period. SOL requires a DSM, its cell size and origin (XY coordinates of the upper left corner), as well as the latitude. Although the latitude can be introduced as a map, with values varying along the cells of the DSM, at a local scale a mean latitude value can be used. Furthermore, the period of time integration is required as well as the time step for the radiation calculation. The period can be set to an hour or a time interval of a particular day of the year, the whole day, an interval of days in a year or the whole year (fig.5 and fig.6)

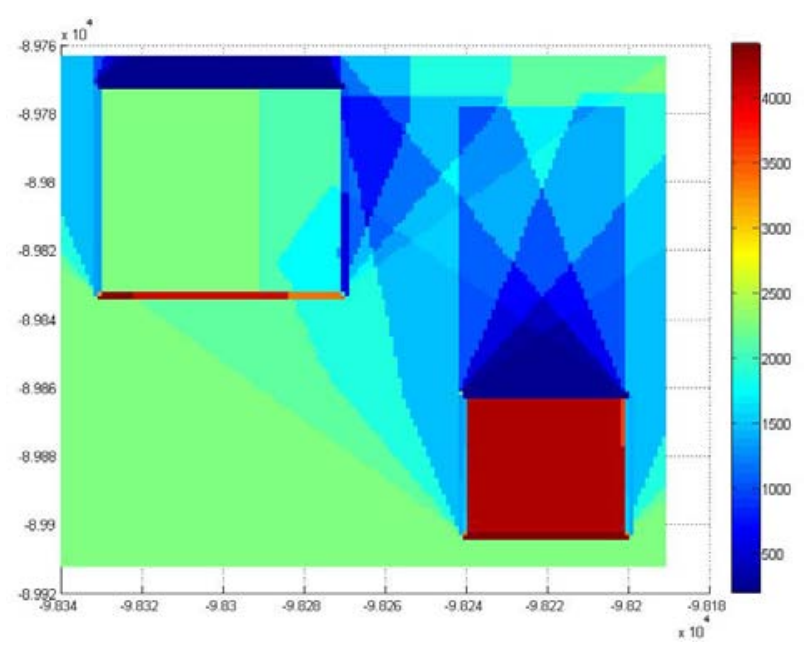

Figure 5. Radiation per unit area with 1 h time steps (January, the $\left.1^{\text {st }}\right)\left[\mathrm{Wh} / \mathrm{m}^{2}\right]$.

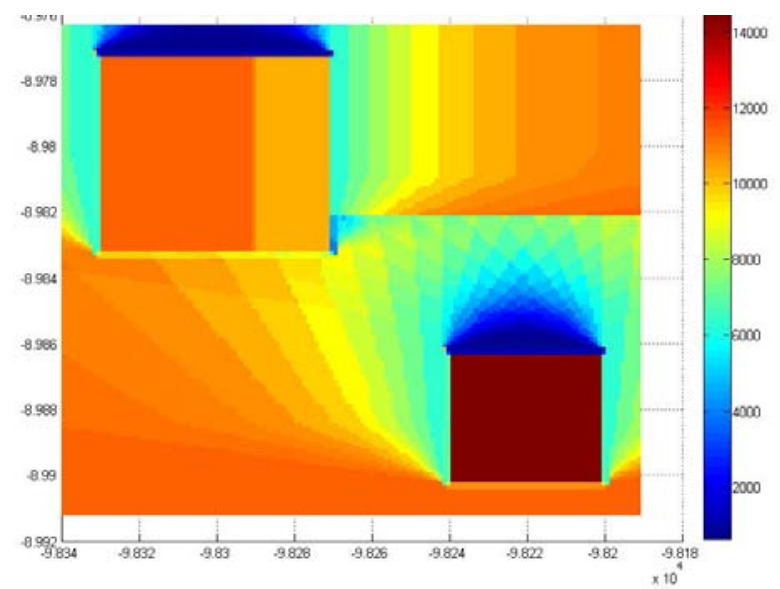

Figure 6. Radiation per unit area with 0.5h time steps (March, the $\left.21^{\text {st }}\right)\left[\mathrm{Wh} / \mathrm{m}^{2}\right]$

For each time step a radiation and a binary shadow map are calculated for the whole DSM and multiplied with each other yielding a sun radiation map for the ground and for all nonvertical surfaces. On the façade the sun radiation is multiplied by the values of the illuminated vertical area in each cell. Also the radiation per square meter is determined in these cells. If there is more than one time step involved, the resulting maps are added (fig. 7). Relevant for the 3D solar radiation model is the 'total radiation' and the 'radiation per square meter' maps. The 'total radiation' map presents the sun radiation that reached each XY position during the period. Façade cells present the sun radiation that reached the vertical column in the XY position of the cell. The 'radiation per square meter' map presents on the façade the total radiation in the vertical column divided by its height above ground. Shadow heights on façades are compiled for each time step in tables containing only the façade cells. This allows to know if a particular point on the façade was in the shadow or not at a particular time according to its height.

The final output of the routine consists on several maps and tables for integration in GIS software where the 3D model is built concealing LiDAR 3D data and the sun radiation values for roofs and façades (fig.8). For single time steps also the shadow on the façades can be represented recurring to the shadow height attribute of the façade cells (fig. 9).

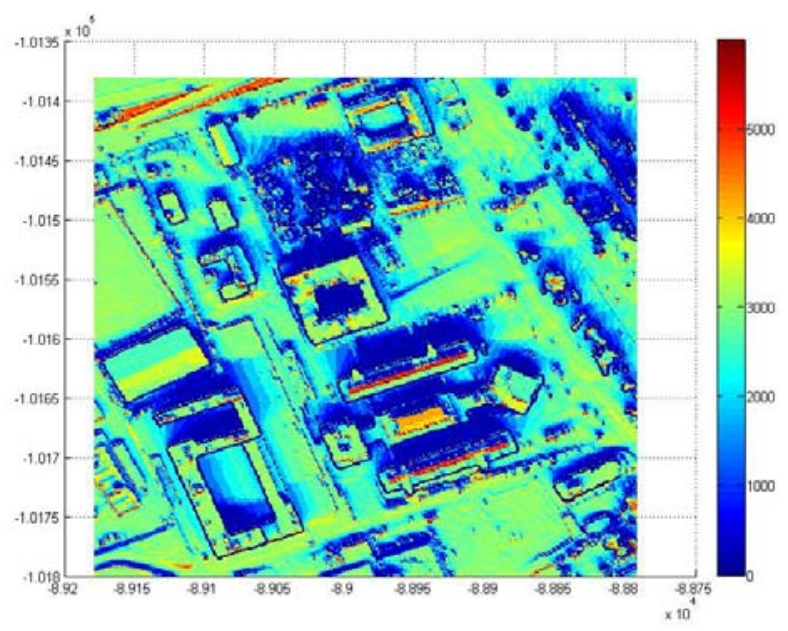

Figure 7. Radiation map without façades for January, the $31^{\text {th }}$ based on LiDAR data $\left[\mathrm{Wh} / \mathrm{m}^{2}\right]$.

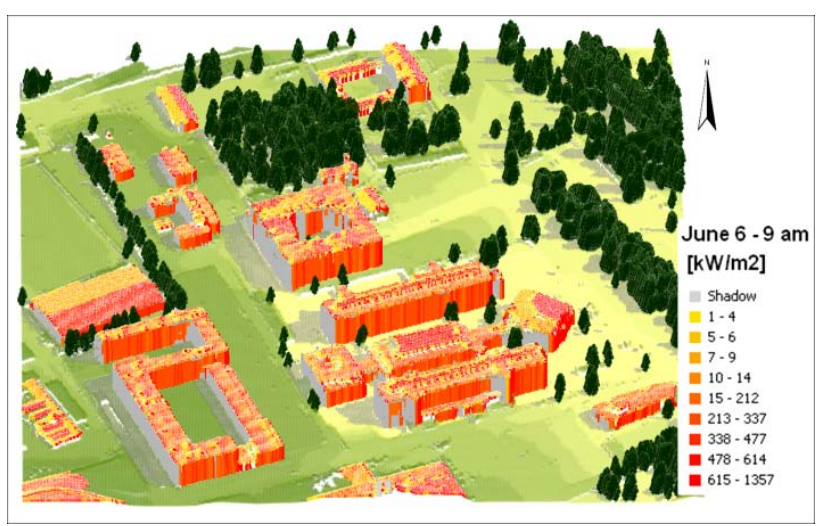

Figure 8. 3D Solar Radiation Model for June, the $6^{\text {th }}, 9$ a.m showing the shadows and the sun energy per square meter. Model based on LiDAR data. 


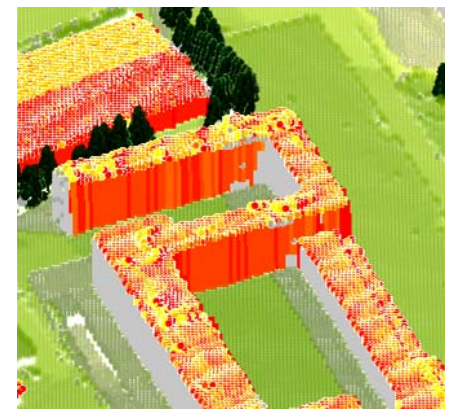

Figure 9. Detail of the 3D solar radiation model showing | façades partially in shadow (June, the $6^{\text {st }}, 9$ a.m).

\section{CONCLUSION}

The objective of generating a 3D local scale solar radiation model for application in urban environments was satisfactory achieved recurring to a DSM obtained from LiDAR data. A shadow algorithm was developed that yields shadow heights in façades or other sun light obstacles, allowing computing the solar radiation at a partially shadowed façade vertical column. Conditioned by the information content of the input data the urban landscape had to be generalized in several ways as follow.

It has been assumed that the urban landscape is composed by ground and other shadow casting objects (trees and buildings).

Slope maps were produced to detect very steep regions that, in an urban context, probably correspond to vertical surfaces. The ones higher than 3 meters were considered building façades.

For the solar model all trees were considered solid shadow casting objects.

A segmentation of the non ground data in trees and buildings was not relevant for the solar radiation calculation and occurred only before the generation of the 3D model in ArcScene (ESRI).

All buildings were considered to have vertical façades without balconies or other small architectural elements. The diversity of façade materials was also not taken into account.

Façades were considered to be one cell size deep, meaning, for a $1 \mathrm{~m} \times 1 \mathrm{~m}$ raster DSM, the façade is a $1 \mathrm{~m}$ deep wall. For the purpose in view, this was not much relevant.

Comparing with the footprints of buildings obtained by photogrammetry, the detected façades reveal errors of the LiDAR DSM data in façades very close to each other, probably due to multi-path effects.

The solar radiation model is prepared to accept a reflectance map that can be used instead of an unique reflectance value for the whole DSM area. This factor affects the reflected parcel of sun radiation. Such a map will be produced by classification of aerial images according to the reflectance of roof materials. For the façades a similar concept could be applied as long as a classification of the façades is feasible.

In spite the limitations LiDAR is a very rich source of data for a solar radiation model. The mentioned generalizations could be reduced if an urban $3 \mathrm{D}$ model was available in an easy to process format. The next step of the project consists on producing a detailed urban 3D model of the studied site and developing a strategy to transform the results obtained with the LiDAR DSM to corresponding façades, allowing adding energy attributes to the buildings of the model.

\section{REFERENCES}

Astronomical Almanac for the Year 2011. 2010. Washington: US Government Printing Office. ISBN 978-0-7077-41031

Carneiro, C., 2011. Extraction of urban environmental quality indicators using LiDAR-based Digital Surface Models. École Polytechnique Fédérale de Lausanne, PhD Thesis

Fu P., Rich P.M., 1999. Design and implementation of the Solar Analyst: an ArcView extension for modeling solar radiation at landscape scales. Proc. IX Annual ESRI User Conference

Hofierka, J., Súri, M., 2002. The solar radiation model for Open source GIS:implementation and applications. Proceedings of the Open source GIS - GRASS users conference 2002 - Trento, Italy, 11-13 September 2002

Jochem, A., Höffler, B., Rutzinger, M., Pfeifer, N., 2009. Automatic Roof Plane Detection and Analysis in Airborne Lidar Point Clouds for Solar Potential Assessment. Sensors 2009, 9, 5241-5262; doi:10.3390/s90705241

Kumar L. et al, 1997. Modelling topographic variation in solar radiation in a GIS environment, Int. J. Geographical Information Science 11, 475-497

Ratti, C., Richens, P. 2004. Raster analysis of urban form. Environment and Planning B: Planning and Design 2004, volume 31, pages 297- 309 DOI:10.1068/b2665

Šúri, M., Huld, T.A., Dunlop, E.D., Ossenbrink, H. A. 2007. Potential of solar electricity generation in the European Union member states and candidate countries, Solar Energy 81, Issue 10, October 2007, Pages 1295-1305 doi:10.1016/j.solener.2006.12.007 